\title{
Screen Position and Proprioception
}

\author{
Marc Boucher
}

My contribution to critical and artistic dialogues within the intersecting fields of dance and screen-based images consists in examining the role of peripheral vision in the perception of dance in artistic contexts where projections are used. There is, as I will point out, sufficient evidence from phenomenological and neuro-physiological accounts to conclude that motion perception is affected by peripheral visual perceptions. Consequently, it is maintained that the spectator's experience of dance, especially when screens are involved, depends to some degree on peripheral visual perception, which in turn contributes to proprioception. In the installations that I will discuss here, the viewer's proprioception, or ability to sense his or her body's position, motion, and equilibrium, is addressed according to the way the screens are placed in relation to him or her. As with staged dances where projections are used, we will concern ourselves with the relationship of the dancer to the screen as seen from the seated viewer's perspective. Projection screen installations combining live dance performance will also be looked into. My interpretation of "screendance" therefore does not refer to dance film or dance video. Instead, I investigate the perceptual contexts where the screen can be said to be part of the scenography and, likewise, the projection part of the choreography. With digital multimedia, the distinction between scenography and choreography can be blurry, and many artists aim precisely to meld them together. What constitutes a screen now encompasses much more than the standard white flat rectangle.

The question of image content is certainly not irrelevant here, but it is not my main concern. What is of prime importance in my analysis is the dynamic value of the images that fall on the viewer's retina: how the visual field is filled and how that affects the viewer's proprioception. The question I wish to address most precisely is how peripheral visual perception informs proprioception in such a way that it allows the spectator to feel movements that are not of his or her making as if they were his or hers. ${ }^{1}$

Before we go any further, a primary distinction must be made between two different yet complementary vision systems, central vision and peripheral vision. Although one learns in high school about the "rods" and the "cones"- the latter's sensitivity to form and color, and the former's to contrast and movement-little mention is ever made of them again. Were it not for the needs of flight simulators, the research into peripheral vision would certainly not be as rich as it is now. ${ }^{2}$ What has emerged from such research is deeper knowledge concerning the intimate connection between vision and balance. The Central Nervous System (CNS) relies on visual cues from the environment in order for us to not only locate ourselves in it, but to move in it. The CNS has no direct access to the world; it therefore must make 
internal models and hypotheses about it, and these "representations" are then verified through our ability to perform diverse tasks: standing without falling over, walking across the room without tripping over this or crashing into that. In certain contexts, it is difficult for the CNS to create an effective internal model because of conflicting information from the senses. ${ }^{3}$ But the body, so to speak, has to learn how to cope with conflicting sensory information. In other words, top-down cognitive factors must eventually override the hard-wired response mechanisms. Cars, escalators, elevators, boats, trains, midway rides, and IMAX theaters can provide puzzling sensory information to the CNS: we see movement that we do not feel, or we feel movement that we do not see. Screen projections can make us feel as if they were our own movements that are not.

With this in mind, in the first two sections of my article, I will explain how proprioception and vision are interrelated in such a way as to give rise to such paradoxical sensations of movement. The illusory feeling of movement, that is to say when there is no actual physical engagement on the part of the perceiver to account for it (i.e. vection), will be discussed, as it provides an insight into the workings of sensory perception that differ from the mundane understanding of the senses. Having explored the relationship of vision to kinesthesia, I shall, in the third and fourth sections, present various screen based installation and scenographies that show how artists arrange the different media scores so that they work together towards immersion.

\section{Proprioception}

In his famous and influential sensory system classification, Charles Sherrington defined proprioception in dialectical relation to exteroception and interoception. ${ }^{4}$ In nineteenth-century epistemology, the distinction between inside and outside, self and world, was deemed absolute and self evident, which is not so much the case today. Yet such a naïve conception is apparently as inescapable as the one according to which we have five distinct senses. When there is a lack of deeper insight, including scientific knowledge, as to how the senses are interrelated, "common sense" understanding prevails insofar as it is deemed useful in everyday contexts. Proprioception literally means perception of self, of one's own body. It has to do with the muscular sensations associated with body and limb position and motion, and sense of balance: in other words, weight, motility (the variations of relative position of limbs and body segments to one another), mobility, and equilibrium. Proprioception results from the integrated inputs of various types of receptor cells in muscles, tendons, joints and inner ear; these provide information of a mechanical nature, that is to say in terms of vibration, elongation, tension, variation of position, and linear and angular acceleration as perceived by various specialized receptor cells in the corresponding tissues.

The body not only perceives itself as being in space, but also as moving in it, primarily through its constant struggle with gravity. Kinesthesia, or sense of 
movement, refers specifically to the sensations that accompany our movements as we generate them, and is usually defined as a subset of proprioception. In Sherrington's system, exteroception refers to the five canonical senses (sight, hearing, smell, taste, and touch) and literally means perception of exterior objects. This commonsensical view is not unproblematic-especially with touch, as Maurice Merleau-Ponty and others have pointed out. In the act of taking one hand in the other, we are at once touched and touching, receptive and active, object and object. Touch does not merely "passively" register "external" objects. It also has a haptic component: grabbing and holding objects involves complex feedback mechanisms, in which action and perception are intimately woven together. Feedback mechanisms are also at the heart of the postural control system, which is now generally considered part of proprioception. We have seen that proprioception, by including postural control, effectively ends up relying on senses defined as exteroceptive (vision and balance). ${ }^{5}$

Visual cues are highly important in affording the possibility of locating oneself in space and moving in it. Especially important are cues from peripheral vision, to the extent that, for example, screen position matters significantly in regard to a viewer's experience. Suffice it to say, for now, that a deficient peripheral vision can dramatically affect balance in seeing subjects. Blind persons have developed a much keener ability to rely on the vestibular apparatus (inner ear) and pressure sensitive plantar receptors in the foot, and hearing (echolocation) in their interactions with the environment. ${ }^{6}$ In postural control, sensorimotor activity involves the adjusting of motor commands to sensory perceptions through feedback loops in the cerebral cortex; the existence of multiple loops between various cerebral centers is suspected. ${ }^{7}$ Feedback is at play in motility, perception, and postural control. The latter allows us to position ourselves, move, and act in the physical world according to internal models the brain elaborates, and through which it compares its predictions with reality. ${ }^{8}$ Feedback loops allow the brain to work through its internal modeling of motor space, linking exteroception, proprioception, and sensorimotor activity in the process. Proprioception can also be defined as the perception of the body itself as spatial, how it occupies space and moves in it. Thinking of proprioception as one of the sense modalities is problematic, especially since proprioception is arguably the very condition of possibility of sensory perception. In other words, proprioception is the very ground to sensory perception as it provides the a priori "sense of self" or of embodiment. ${ }^{9}$

\section{The relationship of vision to kinesthesia}

We have seen that vision is highly important to proprioception, defined as including postural control and kinesthesia, and recalled the distinction between central and peripheral vision. Peripheral vision is intimately tied to proprioception as it provides visual cues for the CNS in order to establish our position in space and control our movements and posture in it. Though the distinction between proprioception and kinesthesia may seem a little abstract, however, we intuitively know that feeling our body as our own and feeling ourselves in motion are different sensations. Also called 
"sense of movement," kinesthesia results from the variations in tension of muscles and tendons, and changes of angles of articulations as perceived by specialized receptors in those tissues. Accordingly, kinesthesia includes sensations obtained by variations in body and limb positions, relative to one another and relative to exterior space. Kinesthesia relies on vision in ways that are beyond our awareness, and without peripheral vision input, equilibrium becomes difficult to maintain. We can, however, experience kinesthesia in darkness, or in silence, or even both-in other words, either with or without the contribution of vision or audition.

In the context of film viewing in a cinema theater, moving images produce kinesthetic sensations in viewers as they would in any given situation where our movements result in varying sequences of moving images impressed on our retinas. Through the interplay of bottom-up and top-down processes, ${ }^{10}$ the CNS attributes the cause for the movement of the images as being ours or not ours. Visual impressions play an important role in the complex process of integration of spatial and bodily perceptions. We perceive through the corner of our eyes an astounding quantity and variety of moving visual patterns and objects, either walking down a busy street, or driving through it in a car. Some of our responses are automatic, while others depend on our degree of attention. In any case, the CNS' internal modeling of the situation must conciliate kinesthetic and visual sensory information. The perception of the relative movements of objects surrounding us must be coherent with our own body perception. The CNS processes retinal input, which it compares with other sensory input.

"Optical flow" is also a very important, if not the most important component of peripheral vision input. It has to do with how visual patterns glide across the retina, according to the movement of the perceived object, and to our own movement relative to the perceived object. Both movements (ours and the object's) are involved when we move towards something that is also moving towards us, or away from us, or in a different direction. Theorized in the 1940s by American psychologist J.J. Gibson, optical flow provides information that helps us determine the direction we are moving based on where we are looking. It can be easily understood as motion blur as illustrated in a still image; it is photography's way of showing movement direction and speed. A still image from a camera following a moving subject can therefore provide two sets of flow information. Moving vehicles can provide puzzling sensory information to the CNS: we see movement that we do not feel, or we feel movement that we do not see. Moving images, especially screen projections, can make us feel as if they were our own movements that are not. The visual and vestibular systems can interact in such a way as to cause the visually induced illusion of self-motion, or visual "vection." It is not a visual but a proprioceptive illusion, and it can be influenced by cognitive factors, that is to say top-down mechanisms, or learned behavior.

The nearly uniform motion of a large part of the visual field causes the subjects to feel that the motion relative to it is their own; therefore, vection occurs. Vection, which was first experimentally studied by Ernst Mach in 1875, is still not fully understood; ${ }^{11}$ watching a high-speed chase from the driver's perspective in a film, 
however, can provide a good empirical example of the phenomenon of vection, which heightens the impression of being in the driver's seat. It provides the feeling of "being there," in other words of "presence" defined as the perceptual illusion of nonmediation. ${ }^{12}$ Most of us have experienced vection in real life contexts, perhaps when suddenly realizing that it's not the train that we are in that is departing, but the one on the next track. Another instance would be while we are stopped at a traffic light. In this case we may feel as if moving backward if the car in the next lane starts off first. In these situations, we are made to feel "as if" we are moving on the basis of the CNS' interpretation of the visual cues and in response to contradictory sensory information. Since vision is a dominant sense, the CNS assumes that the perceived movement, with its optical flow pattern, results from the subject's motion despite the fact that there is none. Vection can, however, cause discomfort to some individuals, akin to motion sickness, whether in a flight simulator, a Cinerama theatre, an IMAX theatre, or a virtual reality simulation.

When information from the visual and equilibrium systems concur, as they usually do, the optic flow impressed on the retina agrees with input from the vestibular system. The latter acts as the body's plumb line and gyroscope, registering changes in position in relation to the gravitational field as well as in acceleration. When we walk down the street, we do not perceive lampposts and buildings as whirling around, but ourselves as moving about them. This follows the rule that information from exteroceptive sense modalities "comes into a complex intermodal relationship with somatic proprioception to form a coordinated and intermodal sensory feedback."13 From hereon, I will investigate the viewer's relationship to screens depending on whether his or her perspective follows the traditional frontal model, or is based on more recent installation forms, where one is free to move about the screens variously deployed.

\section{Screens on stage}

Dancing on screen takes us back to the very beginning of cinema, in 1895, with Annabelle Serpentine Dance performed for the camera by one of the many imitators of Loïe Fuller's style. Dancing with screens takes us to at least July 23, 1965, with Cunningham's Variation $V$. This intermedia extravaganza included various film projections by Stan VanDerBeeke and video projections by Nam June Paik on four screens, and a background cyclorama. With Variation $V$, we can start thinking about the idea of scenography of screens, and reflect on how projected moving images relate spatially and dynamically to the performers and viewers. Interestingly, Variation $V$ was closely followed, on December $2^{\text {nd }}$ of the same year, by Formes disponibles, choreographed by Canadian modern dance pioneer Françoise Riopelle, and aired on Radio-Canada. It featured dancers performing in front of two movie screens, and a cyclorama at the very back. Those screens were laid out at angles in the television studio space, and the projected moving images gave different perspectives on the dance. 
Since 1965, screens have become ubiquitous along with new media technologies, while dance became ever more diverse and sophisticated. Intermedia is practically mainstream nowadays, while Fluxus, sadly, has not made substantial inroads into shaping artistic sensibility of audiences, in my opinion. Proprioceptive properties of moving images in performance contexts need to be addressed by the artistic directors of projects that involve not only dance and projections, but also dance and interactive technologies, projection mapping and computer vision.

Thanks to the use of video projectors, which has become common in theaters in the last two decades, the visual background of the stage can easily be provided with endless dynamic properties. Dance and film projections have been used in combination in the past, but infrequently so. Portable video recorders and digital video editing rapidly made interdisciplinary ventures combining dance and moving image projections quite accessible. The latter have at times overshadowed the dance, but nonetheless made possible new forms of multimedia dance. With projection mapping, a technique that makes it possible to use three dimensional objects as projection screens, the dancer can be transformed into a screen on which visual patterns and virtual costumes can be displayed. Klaus Obermaier, working in collaboration with dancer and choreographer Chris Haring on a project called D.A.V.E., used projection mapping with fantastic results at the turn of the millennium.

What's novel about D.A.V.E. is the concentration of the projections on the body in motion while avoiding conventional spatial and screen projections. You don't think about the video anymore; it just belongs to the body. It's a part of the body, or rather the performer is part of the video. The boundaries grow indistinct and are deactivated. Video projection, physical presence and acoustic environment thus blend into a symbiosis and create their own new reality: D.A.V.E. - digital amplified video engine. ${ }^{14}$

Along with sophisticated and powerful projectors came new image making techniques, which allowed not only interactive moving images to be generated in real time, but to direct them precisely at moving performers. Dancers become display surfaces that are not only moving through space but are constantly changing their shape. Obermaier combined frontal and background projections in his interactive dance and media performance titled Apparition (2004). The outline of the dancers was analyzed by a motion tracking system, the technique of projection mapping allowing projections to be targeted exactly on the bodies. These moving images are generated in real time to fit within the silhouette of the dancer, the motile area whose outline is detected by the tracking system. This frees the dancer from the constraints of being in the exact spot and in the precise shape which earlier methods of projection mapping imposed, as used in D.A.V.E. and in other contexts since the 1960s. As Obermaier writes on his website :

...the real-time system for generating visuals developed for APPARITION is built on top of computational processes that model and 
simulate real-world physics. The inherent kinetic properties of these simulations inspired our view that the overall interactive system is much more than simply an extension of the performer, but is a potential performing partner. The independent behavior of the physical models for example is not 'controllable' by the performer, but can be influenced by his or her movement. This interplay between dancer and system and how one begins to understand the properties of the other has been crucial to the conceptual and aesthetic development of the work; helping give shape to the choreography and underpinning its dramaturgy. ${ }^{15}$

Obermaier's aesthetics in Apparition are geared towards immersion, with the seamless combination of frontal projections of motion-mapped images, and almost ten meters wide background projections. We are lead to kinesthetically empathize with the dancers, which can be seen as protagonists in a dynamic visual drama. The setup for Apparition allows an almost seven-meter wide projection space upstage, narrowing to a pinpoint at nine meters downstage, where the projector is hung. For the background, two rear projectors are used to cover a close to 40-square meter screen area. Interactivity here is at the core of the relationship between the dancer and the projected image, which merge in a visually and dramatically coherent whole. Figure and background are distinctly set off against one another; while the central vision is focusing on the dancer, the peripheral field is filled with congruent dynamic content. The flowing quality of the movement contributes to the hypnotic effect of the ensemble, which many spectators mention. In one specific sequence, the projected patterns of particles moving on the screen flow towards a center that is determined by the position of the dancer in front of it, thus inducing intense vection. This gives the illusory proprioceptive sensation of being drawn in, as if taken to a point lying beyond the screen. In this stunning multimedia choreography, the spectator's visual field is immersed in movement from two qualitatively different sources: movement of the dancer that addresses foveal vision and attention, and movement of the surrounding images falling in the peripheral field. The merging of the dynamic impressions from these two sources corresponds to a merging of the senses brought about by the interrelation of foveal vision, peripheral vision, proprioception, and kinesthesia.

\section{A palette of screens}

Floor projections, often on white marley, are also used in live multimedia dance. The audience should, however, then be provided with an elevated vantage, since the stage floor becomes in effect the backdrop. Upstage naturally lend itself to be read as upwardness, and downstage as downwardness. The dancers will be in direct contact with the floor most if not all of the time, unlike frontal and upright situations, where foreground and background are set some distance apart, up to several meters. In other words, the difference between high angle and frontal propositions can be likened to that between relief and free-standing sculpture. The 
physical and virtual dimensions will appear as fusing together. Most sections of Mortal Engine (2008) exemplify this type of proposition, with the added feature that it was presented on a raked stage. Mortal Engine is a "dance-video-laser performance using movement-and-sound-responsive projections ${ }^{\prime 16}$ by choreographer Gideon Obarzanek, interactive system and visual designer Frieder Weiss, and the Australian contemporary dance company Chunky Move.

This ingenious sloping stage ... acts as a giant screen for the lights and abstract images to be projected onto. [The dancers] are like magnets moving across a giant Magna Doodle. Where the dancers go, their smudges follow. As the shadows and performers seem to morph into one another it is difficult to distinguish between that which is alive and that which is engineered. ${ }^{17}$

Multimedia may bring new life to raked stages, as they provide a surface on which both bodies and images can coexist, serving as background and ground. When the stage is sunken, as in a theater in the round context, spatial references of up and down become altogether irrelevant; there is no absolute reference for upstage and downstage. For example, consider Glow (2006), "an illuminating choreographic essay" 18 by choreographer Obarzanek and software creator Weiss, in which the audience surrounds the dancer on all sides. In this interactive context, the dancer is immersed in the visual imagery she brings forth through her very own movements.

[She] creates a world of light around her as she moves.... Her arm sweeps white light around the stage floor like small ridges of sand. Later she will be part of the pattern of black fretwork sweeping across a nowwhite floor. Often her body is scored with faint lines like the ripples in water silk. At times she seems to be morphing into light or, at one point, being edged toward the boundary of her rectangular world by dark, shifting shapes. ${ }^{19}$

There is some similarity here with the projection mapping methods and technology used for Obermaier's Apparition, both being custom made. In Glow, "Mr Weiss' system uses image-processing techniques to 'find the outline of the body and connected body parts.' This data is then fed into his 'palette' of computer algorithms which then create light and video displays projected back onto the dancer and stage." ${ }^{20}$ Finding the outline of the body is one of the properties of computer vision, otherwise known as artificial vision.

Projection mapping (or video mapping) can be thought of as the interface through which the relationship between figure and background in the context of realtime computer-dancer interactions take place. Projection mapping is also called "spatial augmented reality," and all so rightly in the context of Seventh Sense (2011), a work performed by the Taiwanese Anarchy Dance Theatre, with choreography by Chieh-hua Hsieh, and interactive designs provided by Ultra Combos new media agency. This piece can be described as a performance in a mixed-reality environment: in other words, a space where digital objects exhibiting physical properties and 
dancers interact in real time. In mixed reality performance, space and movement from virtual and physical world are interconnected, and can provide the feeling of immersion.

The stage for Seventh Sense is a white open-sided cube, with projections on the floor and three sides. It also is an interactive environment, a Cave automatic virtual environment (CAVE), which can contain not only the performers but also some members of the audience, allowing them to share the experience in the interactive space. At the beginning of the performance, two dancers move in pools of colored light which display amoeboid movement, like gelatin blobs, crawling and swimming, or as some form of ectoplasm sticking to the dancer. Then a grid pattern fills the space, a cubic landscape in which the squares grow and revert to their original size in sequence, according to the motion of the dancer. The grid landscape then behaves as if it was keeling over from one side to the other, in response to the dancers movement and location. The displayed horizontal and vertical lines do not correspond to their physical equivalents. Sensation of body weight provides a reference to verticality denied by the visual display. Vection is induced in the viewer given the contradiction between visual and proprioceptive inputs. Another visual pattern used in Seventh Sense is that of clouds of particles swishing around, similarly as in Apparition, but this time filling a three dimensional space, and not just the background. With the combination of these last two displayed visual pattern behaviors, one feels is as if the CAVE were floating on some invisible stormy sea.

The distinction between performance space and installation space is also blurred in Rebecca Allen's The Brain Stripped Bare (2002), which calls for two performers, appearing in the flesh, as shadows behind the screens, and as images on the screen. The spectators can deambulate through the 35-foot wide circular space, which is ringed by five large projection screens.

Surrounded by a circle of screens the audience is free to shift their point of view. Live performers merge with shadows, projected images and sounds, revealing stark human forms that move in startling and perplexing ways. This creates a raw, very physical yet illusory interactive experience that connects an audience to a performance in a way not previously explored. ${ }^{21}$

One of the screens in Steve Paxton's Phantom Exhibition (2009) is suspended parallel to the floor, which provides an unusual perspective on the dance appearing on it, previously shot from below through a glass floor. This creates a perceptually correct situation, though paradoxically one is otherwise never exposed to it.

Five large screens surrounding the exhibition space show images of Paxton and other performers moving according to that method [contact improvisation], as well as dance moves simulated with computer graphics, along with poetically rhythmical explanatory narration. Within this overwhelming visual setting, the visitor perceives 
with all his senses the relationship between the human body and gravity. ${ }^{22}$

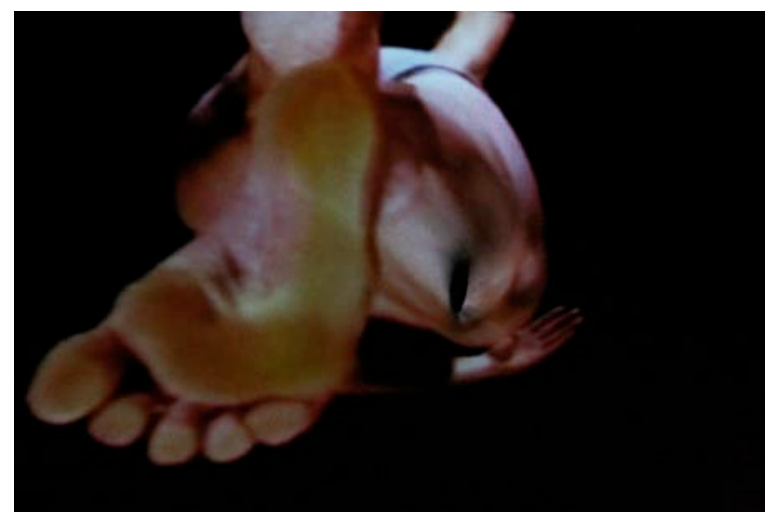

Figure 1:

Still from Phantom Exhibition (2009), dir. Steve Paxton.

Image courtesy of the artist.

In these installations, which are not interactive, the postural system of the spectator is nonetheless addressed, since she or he has to maintain body equilibrium through perceptual cues provided by both the physical space and the virtual space of the moving images on the screen. Overhead projections can be straining on the viewers neck, which is why Montreal's Satosphere usually provides cushions rather than seats. The projections inside this eighteen meters wide spherical dome, whose apex is therefore higher up than in a planetarium, are overwhelmingly large and create an illusion of depth quite different from that provided by $3 \mathrm{D}$ glasses. For its inauguration, a dance and projection piece was shown, titled Intérieur, and billed by its artistic directors Marie-Claude Poulin and Martin Kusch as "one of the rare dance-andmedia performances in the world to be specifically conceived for an immersive environment" 23 (motion mapping was not involved).

In the middle of the space, at a podium, we can see a bustling woman.... In the dome, vast like her thoughts, her secrets are amplified, her fears increased tenfold, her personality multiplied.... Skies of liquid architecture and textures, orbital movements and navigations in imaginary geometries, will alter the perception of gravity. Above the spectators' heads and all around them, images will seem to charge at them: liquid textures possibly referring to flesh, faces anxious and oppressive, running along the walls of the dome. ${ }^{24}$

Sadly, the event generated as much hype as disappointment, but the fundamental problem it posed is a difficult one and yet to be resolved, if it can ever be. It concerns the integration of performance to projected moving images in a space that visually dwarfs the performers. The artists may find it useful to ask themselves questions such as those Obermaier is reported to have had in mind before and during the making of Apparition:

What choreography emerges when software is your partner? / When virtual and actual images pace share the same physics? / Where 
everything that moves on the stage is both interactive and independent? / And any form, dancing or still, can be transformed into a kinetic projection surface? ${ }^{25}$

It is always possible to create newer stage/screen environments where dance interacts with images without relying of virtual immersion technology or interactivity software, as Benoît Lachambre did with Is You Me (2008). In this work, the partly raked stage becomes an augmented and ephemeral space, where Laurent Goldring's real-time drawings are improvised in response to the movements of dancers Lachambre and Louise Lecavalier.

\section{Conclusion}

In works for the stage, scenography can be thought of as an installation through which the performers evolve, and in which the spectators can subjectively project themselves, as is the case with film viewing in a cinema theater. Vitarama, a filming and projection system involving eleven cameras in the shooting and eleven corresponding synchronized projectors, was designed for the Perisphere pavilion at the 1939 World Fair in New York. ${ }^{26}$ Vitarama was developed by Fred Waller, who discovered that spatial perception depends mostly on peripheral vision while experimenting with ways to improve U.S. Army flight simulators. He realized that a curved panorama is more efficient than a flat one, as the visual field is also curved, all of which led to the Cinerama - the IMAX of the fifties, so to speak-which was soon superseded by $70 \mathrm{~mm}$ wide-screen film technology.

Early on in the twentieth century, the Russian avant-garde artist and composer Mikhail Matyushin (1861-1934) conducted experiments in order to demonstrate that the broadening of visual sensibility allows for the discovery of a new "organic substance" and rhythm in the apprehension of space. He announced in a 1923 manifesto the program for a research group called Зорвеd (Zorved: Zor = see; ved = know) that would become the Collective for Expanded Vision in 1930. Work was centered on the goal of expanding human vision to a full 360 degrees range. Despite the preposterousness of that quest, experiments were carried out with a degree of scientific rigor. The concept of expanded or amplified vision was based on a synthesis of Cubism and of Ouspensky's teachings, ${ }^{27}$ and it was pursued with a kind of mystic zeal, which Malevitch and many others shared. Matyushin studied how the perception of shape and color was dependent on where it fell on the retina. Charts presented at an exhibition in Leningrad, in 1930, show how shapes and colors were perceived from various angles. ${ }^{28}$ As R.B. Elder notes, this "'amplified vision' did not include just the eyes; he expanded it to involve hearing, tactility, and thinking-in short, a kind of conscious synaesthesia." ${ }^{29}$

In artistic contexts, peripheral vision is particularly stimulated when one is viewing staged works where moving projected images replace static backdrops. Large film projections have been used on stage as part of theatrical performances for nearly a century. In the 1920s, Erwin Piscator used projections expressly to bind stage and 
audience in a politically motivated space. Piscator had a cinematic and non-narrative idea of the theater, and he relied on the impact of projected images to bring it about. In his "theater as social education," the stage was a medium that conveyed information by means of collage and montage techniques. For Alfons Paquet's play Fahnen in 1924, Piscator made the unusual choice of projecting images stage left and right. In 1928, Ernst Toller went even further with both lateral and frontal screens for his production of Tolstoi and Shchegolev's Raspoutine, and he capped the set with a silver fabric covered hemisphere. Piscator approached Gropius and the Bauhaus in 1926 to help conceive his Totaltheater project, which planned for slide and cinematic projections that would enclose the whole space, walls and ceiling.

In A Book of Five Rings (circa 1645), the Japanese Buddhist swordsman Miyamoto Musashi's distinguished between looking and seeing. Whereas looking refers to central vision, to focusing intently on an object, seeing is a mode of attention characteristic of peripheral vision, to which one attends in an unfocused yet actively receptive fashion. Musashi stressed that seeing is more important than looking; the distinction between both remains relevant today as it relates to two different ways of paying attention.

The privilege accorded to frontal relationship to images has perhaps a lot to do with the discovery of the laws of perspective, and their systematic application to staged works since the Renaissance. Cinema and television consolidated what likely had already become a cultural preference, since these technologies were based on, and limited to, frontal relationship, except with devices such as those devised by Fred Waller. Screen position relative to the viewer must be taken into account as more and more technological devices and artistic propositions aim their moving images indirectly at the viewer, as the recourse to visual immersion becomes increasingly important with new media. It may be impossible to predict how far this trend will go, but experiments are carried out in order to provide peripheral visual stimulations in domestic settings with specially designed projection systems that turn the side walls of the television room into lateral screens. ${ }^{30}$

For various reasons, shutting out peripheral visual stimulations has proven to be, perhaps by default, a more economical and practical way of dealing with the problem of reconciling peripheral and foveal stimulations in artificial contexts. Nonetheless, many artists use perceptual strategies involving peripheral stimulations, and it is arguably important that they and their audiences educate their knowledge of vision according to phenomenological accounts and neuro-scientific evidence-in other words, learn to appreciate in an embodied manner, or with due proprioceptive awareness, the distinction between looking and seeing. 


\section{Notes}

1. This raises fundamental philosophical issues since the absolute and immutable character of the distinction between self and object is put into question.

2. It was spearheaded in the 1930s, namely through the work of Fred Waller who was employed for this purpose by the American Army. He was later to invent a filming and projection system, the Cinerama, which was in the 1950s the precursor of $70 \mathrm{~mm}$ film. In between, he invented the Vitarama, a system using not three projectors, as with the Cinerama, but eleven, aimed at a curved wall, which happened to be the inside of the Perisphere pavilion at the 1939 New York World's Fair.

3. The CNS can interpret conflicting information from the senses as hallucinations, and since ingestion of poisonous substances can cause hallucinations, vomiting may be triggered, as a sort of preemptive measure.

4. See Charles Sherrington, The integrative action of the nervous system (New York: Scribner, 1906).

5. This challenges the pertinence of the distinction between proprioception and exteroception, if not the capacity of language to describe sensory perception without falling into semantic conundrums. This is better addressed elsewhere, namely in aesthetics, but I hope it will suffice here to state that traditional Western philosophy is grounded on sets of absolute, if not rigid and dogmatic, distinctions, such as between "inside" and "outside." However useful such distinctions are in everyday language, as well as in formal (i.e. computer) language, they impose limits to our understanding of living processes. See Humberto Maturana and Francisco Varela, Autopoiesis and Cognition: the Realization of the Living (Dordrecht, Holland: Kluver, 1980).

6. The awareness or sense of body is obtained in cooperation with vision and equilibrium (vestibular sense); a deficit in one can, in some cases and to some extent, be compensated by reliance on the other. See Oliver Sacks, The Man Who Mistook His Wife for a Hat and Other Clinical Tales (New York: Touchtone, 1998), 47.

7. Posture control also challenges the view that action and perception are separate. Posture is preparation for action; it is expressive, reflects intention, is dictated by culture and various other factors, and always contains an emotion. See Alain Berthoz and Jean-Luc Petit, The Physiology and Phenomenology of Action, trans. C. Macann (Oxford: Oxford University Press, 2008).

8. In other words, it projects onto the world its pre-perceptions and hypotheses. See Alain Berthoz, Emotion and Reason: The cognitive neuroscience of decision Making, trans. G. Weiss (Oxford: Oxford University Press, 2006). 
9. Sacks maintains that proprioception may very well constitute the "fundamental organic mooring of identity - at least of that corporeal identity or 'body-ego', which Freud sees as the basis of self" (The Man, 52). "I feel my body is blind and deaf to itself ... it has no sense of itself" declared Christina, the "Disembodied Lady" who suffered an irreversible loss of proprioception, a rare and puzzling affliction caused in her case by a bout of polyneuritis (ibid., 51) Furthermore, "whenever consciousness begins, it will already be informed by embodiment and the processes that involve motor schema and proprioception." See Shaun Gallagher, How the Body Shapes the Mind (Oxford: Clarendon Press, 2005), 77.

10. "Bottom-up" refers to afferent neural pathways and "top-down" to efferent pathways - sensory input and motor output, if you will.

11. "Visually induced vection is a functional phenomenon and not just a laboratory curiosity because it probably contributes to the veridical sense of movement when walking or while being transported. To date, scientists have not been successful in isolating any single necessary condition except for the presence of optokinetic stimulation in the form of a moving visual pattern that is registered background." Sheldon M. Ebenholtz, Oculomotor Systems and Perception (Cambridge: Cambridge University Press, 2001), 143.

12. Matthew Lombard and Theresa Ditton, "At the Heart of It All: The Concept of Presence," Journal of Computer-Mediated Communication 3, no. 2 (1997), http://jcmc.indiana.edu/vol3/issue2/lombard.html.

13. Gallagher, How the Body Shapes the Mind, 106.

14. Klaus Obermaier, "D.A.V.E," artist website, http://www.exile.at/dave/project.html.

15. Klaus Obermaier, "Apparition," artist website, http://www.exile.at/apparition/background.html.

16. Penelope Broadbent, "Review: Mortal Engine," Australian Stage, March 8, 2009, http://www.australianstage.com.au/reviews/melbourne/mortal-engine--chunkymove-2296.html

17. Ibid.

18. Jennifer Dunning, "Crossing the Border From Light to Human," The New York Times, February 8, 2008, http://www.nytimes.com/2008/02/08/arts/dance/08chun.html?_r=0.

19. Ibid.

20. "Moving to the algo-rhythm," The Age, March 13, 2007.

http://www.theage.com.au/news/technology/moving-to-thealgorhythm/2007/03/12/1173548107497.html 
21. Rebecca Allen, "The Brain Stripped Bare," http://www.rebeccaallen.com/v2/work/work.php?ID=11.

22. "Steve Paxton Phantom Exhibition," Yamaguchi Center for Arts and Media, http://www.ycam.jp/en/art/2009/04/steve-paxton-phantom-exhibitio.html.

23. Martin Kusch and Marie-Claude Poulin, "Intérieur (2010/2011)," http://www.konditionpluriel.org/projects/interieur/.

24. Ibid.

25. Giorgos Stylianou, Monography for the course Multimedia in Artistic Environments Klaus Obermaier (University of Aveiro Department of Communication and Arts, 2011), http://fr.scribd.com/doc/60107297/Klaus-Obermaier-Monography.

26. R. Kroon, AN A to Z: An Encyclopedic Dictionary of Media, Entertainment and Other Audiovisual Terms (Jefferson, N.C.: McFarland \& Company, Inc., 2010), 738.

27. C. Lodder, "Transfiguring Reality: Suprematism and the Aerial View", Seeing From Above: The Aerial View in Visual Culture, eds. M. Dorrian and F. Pousin (London: I.B.Tauris, 2013), 106-107.

28. ZKM Karlsruhe, Matjuschin und die Leningrader Avantgarde (Stuttgart-München; Oktogon Verlag, 1991).

29. R. B. Elder, Harmony and dissent: Film and Avant-garde Art Movements in the Early Twentieth Century (Waterloo, Ontario: Wilfrid Laurier University Press, 2008), 352.

30. For example, MIT Media Lab's Infinity-by-Nine system, Microsoft's IllumiRoom, and SurroundVideo at the BBC's R\&D Production Lab.

\section{References}

Allen, Rebecca. "The Brain Stripped Bare." Artist website. http://www.rebeccaallen.com/v2/work/work.php?ID=11.

Berthoz, Alain. Emotion and Reason: The cognitive neuroscience of decision Making. Translated by G. Weiss. Oxford: Oxford University Press, 2006.

Berthoz, Alain and Jean-Luc Petit. The Physiology and Phenomenology of Action. Translated by C. Macann. Oxford: Oxford University Press, 2008.

Broadbent, Penelope. "Review: Mortal Engine | Chunky Move." Australian Stage, March 8, 2009. http://www.australianstage.com.au/reviews/melbourne/mortal-engine-chunky-move-2296.html. 
Carroll, Noël and Margaret Moore. "Moving in Concert: Dance and Music." In The Aesthetic Mind: Philosophy and Psychology, edited by E. Schellekens and P. Goldie, 333345. Oxford: Oxford University Press, 2011.

Dunning, Jennifer. "Crossing the Border From Light to Human." The New York Times, February 8, 2008. http://www.nytimes.com/2008/02/08/arts/dance/08chun.html?_r=0.

Ebenholtz, Sheldon M. Oculomotor Systems and Perception. Cambridge: Cambridge University Press, 2001

Elder, R. B. Harmony and dissent: Film and Avant-garde Art Movements in the Early Twentieth Century. Waterloo, Ontario: Wilfrid Laurier University Press, 2008.

Gallagher, Shaun. How the Body Shapes the Mind. Oxford: Clarendon Press, 2005.

Karlsruhe, ZKM. Matjuschin und die Leningrader Avantgarde. Stuttgart-München: Oktogon Verlag, 1991.

Kroon, R. AN A to Z: An Encyclopedic Dictionary of Media, Entertainment and Other Audiovisual Terms. Jefferson, N.C.: McFarland \& Company, Inc., 2010.

Kusch, Martin and Marie-Claude Poulin. "Intérieur (2010/2011)." kondition pluriel. Artist website. http://www.konditionpluriel.org/projects/interieur/.

Lodder, C. "Transfiguring Reality: Suprematism and the Aerial View." In Seeing From Above: The Aerial View in Visual Culture, edited by M. Dorrian and F. Pousin, 95-117. London: I.B.Tauris, 2013.

Lombard, Matthew and Theresa Ditton. "At the Heart of It All: The Concept of Presence." Journal of Computer-Mediated Communication 3, no. 2 (1997). http://jcmc.indiana.edu/vol3/issue2/lombard.html.

Maturana, Humberto and Francisco Varela. Autopoiesis and Cognition: the Realization of the Living. Dordrecht, Holland: Kluver, 1980.

Mocan, Rodica. "Klaus Obermaier - 'My work is not simply visualization. It's a totally different thing!'" Ekphrasis 2 (2013): 250-262.

Naimark, Michael. "Spatial Correspondence in Motion Picture Display." SPIE Proceedings 462 (1984): 78-81.

Sacks, Oliver. The Man Who Mistook His Wife for a Hat and Other Clinical Tales. New York: Touchtone, 1998.

Sherrington, Charles. The integrative action of the nervous system. New York: Scribner, 1906.

"Steve Paxton Phantom Exhibition." Yamaguchi Center for Arts and Media. http://www.ycam.jp/en/art/2009/04/steve-paxton-phantom-exhibitio.html. 
Stylianou, Giorgos. "Monography for the course Multimedia in Artistic Environments: Klaus Obermaier." University of Aveiro Department of Communication and Arts, 2011. http://fr.scribd.com/doc/60107297/Klaus-Obermaier-Monography.

Tembeck, Iro. Danser à Montréal: Germination d'une histoire chorégraphique. Sillery, Québec: Presses de l'Université du Québec, 1991.

"Moving to the algo-rhythm." The Age, March 13, 2007. http://www.theage.com.au/ news/technology/moving-to-thealgorhythm/2007/03/12/1173548107497.html.

Vaughn, David. Merce Cunningham: Fifty Years. New York: Aperture, 1997. 